\title{
PROCESSOS DE APAGAMENTO NA FALA DE SUJEITOS COM DISPRAXIA VERBAL
}

\section{The process of speech erasing in subjects with verbal dispraxy}

\author{
Inaê Costa Rechia ${ }^{(1)}$, Ana Paula Ramos de Souza ${ }^{(2)}$, Carolina Lisboa Mezzommo ${ }^{(3)}$
}

\section{RESUMO}

Objetivo: analisar o papel dos fatores linguísticos nos processos de apagamento silábico, consonantal e vocálico na fala de sujeitos com Dispraxia Verbal. Métodos: análise fonológica de sete sujeitos (2:6-4:2), com hipótese diagnóstica de Dispraxia Verbal. Resultados: as variáveis tonicidade, extensão da palavra e classe sonora foram selecionadas como relevantes para os apagamentos silábicos. Além destas, nos apagamentos consonantais, a estrutura silábica também é relevante. Já no apagamento de vogais apenas a tonicidade e a estrutura silábica foram estatisticamente significantes. Conclusão: os dados desta pesquisa sugerem que o pé métrico tende a ser mais corretamente produzido, estrutura prosódica na qual ocorre menos apagamentos. Já as sílabas mais afetadas por apagamentos são justamente as que estão fora do pé métrico.

DESCRITORES: Apraxias; Fala; Desenvolvimento de Linguagem

\section{INTRODUÇÃO}

Considerando a alta prevalência da dispraxia verbal (DV) e de padrão familial ${ }^{1}$, sua caracterização ainda merece estudos mais detalhados. Buscando minimizar a escassa descrição, um estudo com 75 fonoaudiólogos encontrou cinquenta diferentes características, sendo apenas seis coincidentes em $51,5 \%$ das respostas. Dentre as características citadas estão: produções inconsistentes, dificuldade de motricidade orofacial geral, tateio arti-

(1) Fonoaudióloga; Responsável Técnica da Comunicare Aparelhos Auditivos, Santa Maria, RS; Especialista em Transtornos do Desenvolvimento na Infância e na Adolescência pelo Centro Lydia Coriat de Porto Alegre; Mestre pelo Programa de Pós-Graduação em Distúrbios da Comunicação Humana da Universidade Federal de Santa Maria.

(2) Fonoaudióloga; Docente do Programa de Pós-Graduação em Distúrbios da Comunicação Humana da Universidade Federal de Santa Maria, UFSM, Santa Maria, RS; Doutora em Letras: área de Linguística Aplicada pela Pontifícia Universidade Católica do Rio Grande do Sul.

(3) Fonoaudióloga; Docente do Programa de Pós-Graduação em Distúrbios da Comunicação Humana da Universidade Federal de Santa Maria, UFSM, Santa Maria, RS; Especialista em Motricidade Orofacial pelo CEFAC - Pós-Graduação em Saúde e Educação, e em Linguagem; Doutora em Letras: área de Linguística Aplicada pela Pontifícia Universidade Católica do Rio Grande do Sul.

Conflito de interesses: inexistente culatório (busca da produção correta do som pela tentativa dos articuladores), inabilidade para imitar sons, aumento da dificuldade com o aumento da extensão da palavra, erros de sequencialização e em vogais, dificuldades com movimentos voluntários de fala, inteligibilidade reduzida, omissões de sons (Forrest, 2003). Além destes, também foram referidos problemas com vozeamento, controle da nasalidade, prosódia alterada ${ }^{2}$ e diminuição do coeficiente de variação temporal da fala ${ }^{3}$. A alteração possivelmente estaria na transição entre 0 código fonológico (input) e o padrão articulatóriomotor (output) ${ }^{4}$, nível de silabação previsto no processamento da palavra ${ }^{5,6}$. Por isso, o tipo de sílaba, a sua posição na palavra e a frequência desta no léxico da língua são aspectos relevantes na análise da fala de sujeitos com DV ${ }^{7,8}$.

Considerando tais estudos, objetiva-se analisar a interferência das variáveis linguísticas tonicidade, extensão da palavra, classe de sonora e tipo silábico nos processos de apagamento silábico, consonantal e vocálico na fala de sujeitos com DV.

\section{MÉTODOS}

A amostra deste estudo é constituída da análise fonológica da fala de sete sujeitos, com idades entre 2:6 e 4:2 anos, com hipótese diagnóstica de 
DV, trazidos por suas mães com queixa de dificuldades para falar, constituindo, portanto, uma amostra de conveniência.

As mães que procuraram o Serviço de Atendimento Fonoaudiológico na Instituição de origem no ano de 2007, cujos filhos tinham a hipótese diagnóstica de DV, receberam esclarecimentos a respeito dos objetivos gerais e específicos bem como dos procedimentos da pesquisa e assinaram o Termo de Consentimento Livre e Esclarecido. Aquelas, que aceitaram participar, assinaram o termo de consentimento livre e esclarecido, autorizando a divulgação dos dados, salvaguardados os direitos de voluntariado e de confidencialidade da identidade dos participantes.

Todos os sujeitos passaram por exames complementares, realizando avaliação neurológica, otorrinolaringológica e audiológica com o intuito de descartar qualquer tipo de deficiência (critérios de exclusão).

Os critérios diagnósticos foram: presença dos sinais de DV relatados na literatura, sobretudo alterações de vogais ou de acento; presença de tateio articulatório caracterizado por olhar fixo na articulação do interlocutor e tentativa de imitar fonemas movimentando silenciosamente lábios e língua; presença de variabilidade articulatória (foram consideradas distintas produções de uma mesma palavra-alvo); múltiplos apagamentos de sílabas e segmentos; imitação de sons pobre ou ausente; aumento da dificuldade de produção com o aumento da extensão de enunciados e sequencialização pobre de sons (dificuldades importantes de alternar ponto articulatório) induzindo a extensas assimilações.

Todos os sujeitos apresentavam dificuldades em sequencializar movimentos orofaciais de lábios e língua, mesmo por imitação, embora uma certa imaturidade fosse prevista para a faixa etária analisada. Para se chegar a essa hipótese foi considerado como padrão de referência de desenvolvimento típico o corpus de aquisição fonológica do PB sintetizado em Lamprecht et al. ${ }^{9}$, que fornece o perfil aquisitivo do dialeto mais próximo ao das crianças estudadas.

O corpus de fala constituído para essa análise foi obtido pela gravação de interações espontâneas em situação lúdica de cada sujeito com sua mãe e com a terapeuta (15 minutos cada). Ressalta-se que as crianças já estavam habituadas com a terapeuta e procurou-se utilizar brinquedos de interesse das crianças para facilitar a produção de fala. Para as filmagens, utilizaram-se a filmadora Digital Handycam DCR-TRV 130 NTSC da Sony, fita Hi8 Sony e TDK. Tais interações foram transcritas e analisadas pela primeira autora, e conferidas pela segunda.
A terceira autora também conferiu os dados acordando com a hipótese diagnóstica formulada. A segunda e a terceira autoras são pesquisadoras da área de aquisição fonológica e com experiência clínica da área.

A produção correta; assimilação; variabilidade articulatória; substituições idiossincráticas e usuais; apagamentos de consoantes, vogais e sílabas; epênteses; metáteses vocálicas foram identificados na transcrição. Com base no cálculo total dessas ocorrências, foram selecionadas aquelas de maior frequência, visando a uma maior confiabilidade dos resultados estatísticos. Assim, foram definidas como variáveis dependentes: a produção correta do som, o apagamento da sílaba; o apagamento do segmento; as assimilações consonantais; a variabilidade articulatória; as substituições usuais e nãousuais (de classes principais abrangendo os traços [+soante], [+aproximante], como a troca de líquidas por plosivas, e a troca de [+contínuo] por [-contínuo], em especial a realização de fricativas por plosivas ${ }^{9}$. Também foram analisadas as substituições de vogais. As variáveis independentes consideradas foram: tonicidade, estrutura silábica, classe de sons, extensão da palavra e idade dos sujeitos. Para este artigo, foram selecionados apenas os resultados das análises quanto aos apagamentos silábicos, consonantais e vocálicos.

Este artigo é parte da pesquisa "Clínica da Subjetividade nos Retardos de Aquisição da Linguagem Oral" aprovada no Comitê de Ética em Pesquisa da Universidade Federal de Santa Maria, com certificado de apresentação e aprovação no 0117.0.243.000-07.

Os dados de fala foram codificados e digitados em um formulário no Microsoft Access 2003. Esse banco de dados serviu de entrada para o programa estatístico - o Pacote Computacional VARBRUL ${ }^{10}$. Esse conjunto de programas é largamente utilizado em análises linguísticas variacionistas ${ }^{11}$, entretanto, apesar de ser um programa específico para a área da variação linguística, já foi utilizado com sucesso na análise de dados da aquisição de linguagem em vários estudos ${ }^{12}$. Optou-se pelo uso do VARBRUL pelo fato de ele ser capaz de fornecer frequências e probabilidades sobre os fenômenos estudados, além de selecionar variáveis relevantes no processo da aquisição da linguagem.

O Pacote VARBRUL faz a análise probabilística na forma binária. Isto significa que esse programa, por meio de cálculos estatísticos, atribuiu pesos relativos às variantes das variáveis independentes, com relação às duas variantes do fenômeno linguístico em questão, representadas pela variável dependente. 
Ele trabalha com uma margem de erro de 5\%, mostrando que qualquer fator com significância abaixo desse valor não era estatisticamente expressivo. Entretanto, consideraram-se, nesse estudo, também valores de significância superiores a 0,05 que podem ser linguisticamente relevantes, já que esse parecer depende do pesquisador.

Os pesos relativos foram retirados da interação que contém, conjuntamente, todas as variáveis selecionadas pelo programa. Esses fatores são estatisticamente significantes e mostram que têm um papel no fenômeno estudado. Assim, por exemplo, valores próximos a .50 são considerados contextos neutros, nem favorecedores nem desfavorecedores ao fenômeno estudado; enquanto superiores (acima de .60) são favorecedores e inferiores (abaixo de .50) são desfavorecedores.

Nesse projeto, prevê-se a realização de terapia fonoaudiológica que leva em consideração aspectos subjetivos e objetivos. Entre os objetivos está o limite biológico, imposto à comunicação pela DV, o que prevê a descrição fonológica desse quadro clínico.

\section{RESULTADOS}

A Tabela 1 apresenta o peso relativo das variáveis linguísticas que favorecem o apagamento silábico. Nessa variável, foram selecionadas as variáveis tonicidade, extensão da palavra e classe sonora como estatisticamente significantes.

Nota-se que a sílaba pré-tônica, a pré-pré-tônica, a pós-pós-tônica e, a pós-tônica, nesta ordem, são as posições mais atingidas pelo apagamento silábico. Tal favorecimento também foi significante nas poucas produções de palavras polissilábicas, seguidas das trissilábicas, demonstrando que a extensão da palavra interfere de modo fundamental na ocorrência de apagamentos silábicos.

Ao contrário do esperado pela literatura, as nasais e as plosivas foram favorecedoras do apagamento silábico, em oposição ao esperado favorecimento de fricativas e líquidas, indicando que outros fatores são mais determinantes no processo de apagamento silábico do que a classe fonológica. No entanto, o oposto pode ser verificado na Tabela 2 , na qual se verifica o alto favorecimento de líquidas para o apagamento consonantal, seguida da neutralidade das fricativas e, do desfavorecimento de tal apagamento nas demais classes sonoras.

Percebe-se, na Tabela 2, que o onset complexo inicial, coda medial, onset complexo medial e, coda final são, nessa ordem, as estruturas mais favorecedoras do apagamento segmental. Esses dados demonstram que os sujeitos preferem o apagamento do fonema à omissão da sílaba quando diante de estruturas silábicas complexas e de classes sonoras marcadas em termos aquisitivos.

A variável tonicidade se manifestou no apagamento consonantal pelo favorecimento de ocorrência deste em sílabas pós-pós-tônicas. Esse fato sugere que a sílaba extramétrica, não-utilizada na leitura e construção do acento no PB, é o contexto mais favorecedor para tais apagamentos. Em relação ao apagamento consonantal, a extensão da palavra se apresentou neutra para dissílabas e trissílabas e desfavorecedora para monossílabas.

Tabela 1 - Variáveis linguísticas que favorecem o apagamento de sílaba

\begin{tabular}{|c|c|c|c|c|}
\hline \multirow[t]{2}{*}{ Variáveis } & Variantes & \multicolumn{2}{|c|}{$\begin{array}{l}\text { Frequência/ } \\
\text { Porcentagem }\end{array}$} & \multirow{2}{*}{$\begin{array}{c}\begin{array}{c}\text { Peso } \\
\text { Relativo }\end{array} \\
.83\end{array}$} \\
\hline & Pré-tônica & $33 / 99$ & $33 \%$ & \\
\hline & Pré-pré-tônica & $9 / 25$ & $36 \%$ & .74 \\
\hline \multirow[t]{3}{*}{ Tonicidade } & Pós-pós-tônica & $1 / 3$ & $33 \%$ & .68 \\
\hline & Pós-tônica & 12121 & $10 \%$ & .62 \\
\hline & Tônica & $11 / 307$ & $4 \%$ & .31 \\
\hline \multirow{4}{*}{ Extensão da palavra } & Polissílabas & $17 / 56$ & $30 \%$ & .79 \\
\hline & Trissílabas & $28 / 143$ & $18 \%$ & .64 \\
\hline & Dissílabas & $21 / 356$ & $5 \%$ & .39 \\
\hline & Monossílabas & $0 / 160$ & $0 \%$ & - \\
\hline \multirow{5}{*}{ Classe de sons } & Nasais & $6 / 38$ & $16 \%$ & .66 \\
\hline & Plosivas & $33 / 200$ & $16 \%$ & .66 \\
\hline & Vogais e semivogais & $1 / 58$ & $17 \%$ & .45 \\
\hline & Fricativa & $9 / 124$ & $7 \%$ & .44 \\
\hline & Líquidas & $8 / 135$ & $6 \%$ & .30 \\
\hline $\begin{array}{l}\text { Input } \\
\text { Significância }\end{array}$ & & & & \\
\hline
\end{tabular}


Tabela 2 - Variáveis linguísticas que favorecem o apagamento consonantal

\begin{tabular}{|c|c|c|c|c|}
\hline \multirow{2}{*}{$\begin{array}{l}\text { Variáveis } \\
\text { Estrutura silábica }\end{array}$} & \multirow{3}{*}{$\begin{array}{c}\text { Variantes } \\
\text { Onset complexo inicial } \\
\text { Coda medial }\end{array}$} & \multicolumn{2}{|c|}{$\begin{array}{l}\text { Frequência/ } \\
\text { Porcentagem }\end{array}$} & \multirow{2}{*}{$\begin{array}{c}\begin{array}{c}\text { Peso } \\
\text { Relativo }\end{array} \\
.98\end{array}$} \\
\hline & & $22 / 23$ & $96 \%$ & \\
\hline & & $25 / 33$ & $76 \%$ & .96 \\
\hline & Onset complexo medial & $16 / 18$ & $89 \%$ & .91 \\
\hline & Coda final & $7 / 17$ & $41 \%$ & .80 \\
\hline & Onset simples inicial & $37 / 362$ & $10 \%$ & .47 \\
\hline & Onset simples medial & $43 / 305$ & $14 \%$ & .33 \\
\hline \multirow{5}{*}{ Classe de sons } & Líquidas & $94 / 168$ & $56 \%$ & .89 \\
\hline & Fricativa & $21 / 163$ & $13 \%$ & .56 \\
\hline & Nasais & $12 / 87$ & $14 \%$ & .46 \\
\hline & Plosivas & $22 / 254$ & $9 \%$ & .42 \\
\hline & Vogais e semivogais & $1 / 86$ & $1 \%$ & .03 \\
\hline \multirow[t]{5}{*}{ Tonicidade } & Pós-pós-tônica & $2 / 3$ & $67 \%$ & .98 \\
\hline & Tônica & 95/497 & $19 \%$ & .53 \\
\hline & Pré-tônica & $28 / 107$ & $26 \%$ & .53 \\
\hline & Pré-pré-tônica & $1 / 25$ & $4 \%$ & .45 \\
\hline & Pós-tônica & $24 / 126$ & $19 \%$ & .36 \\
\hline \multirow[t]{4}{*}{ Extensão da palavra } & Dissílabas & $94 / 390$ & $24 \%$ & .58 \\
\hline & Trissílabas & $34 / 152$ & $22 \%$ & .51 \\
\hline & Polissílabas & $8 / 41$ & $14 \%$ & .47 \\
\hline & Monossílabas & $14 / 160$ & $9 \%$ & .31 \\
\hline Input & & & & \\
\hline
\end{tabular}

A análise das polissílabas, embora tenda ao desfavorecimento, não permite, pelo baixo input, fazer generalizações sobre o apagamento consonantal nessa estrutura.

Por fim, o apagamento de vogais (Tabela 3), a última variável analisada, demonstrou ser afetado pela tonicidade e pelo tipo de estrutura silábica.

As sílabas pré-pré-tônica e, pré-tônica favorecem este, enquanto as posições tônica e póstônica o desfavorecem. Não ocorreram casos de apagamento de vogal em sílabas pós-pós-tônica. As substituições de vogais não foram frequentes no corpus de modo a produzirem um número suficiente de vezes para análise estatística.

A variável estrutura silábica também afetou os apagamentos vocálicos já que a coda final e medial apareceram como favorecedores a estes. O onset simples inicial foi neutro e o medial, desfavorecedor. Não houve apagamentos de vogais em onset complexo.

Tabela 3 - Variáveis linguísticas que favorecem a apagamento vocálico

\begin{tabular}{lcccc}
\hline Variáveis & Variantes & \multicolumn{1}{c}{$\begin{array}{c}\text { Frequência/ } \\
\text { Porcentagem }\end{array}$} & $\begin{array}{c}\text { Peso } \\
\text { Relativo }\end{array}$ \\
\hline \multirow{2}{*}{ Tonicidade } & Pré-pré-tônica & $15 / 25$ & $60 \%$ & .99 \\
& Pré-tônica & $12 / 97$ & $12 \%$ & .86 \\
& Tônica & $8 / 478$ & $2 \%$ & .40 \\
& Pós-tônica & $1 / 115$ & $1 \%$ & .33 \\
& Pós-pós-tônica & $0 / 3$ & $0 \%$ & - \\
\hline \multirow{2}{*}{ Estrutura silábica } & Coda final & $2 / 17$ & $12 \%$ & .93 \\
& Coda medial & $5 / 33$ & $15 \%$ & .87 \\
& Onset simples inicial & $26 / 362$ & $7 \%$ & .55 \\
& Onset simples medial & $3 / 303$ & $1 \%$ & .36 \\
\hline Input & Onset complexo inicial & $0 / 23$ & $0 \%$ & - \\
Significância & Onset complexo medial & $0 / 18$ & $0 \%$ & - \\
\hline
\end{tabular}




\section{DISCUSSÃO}

Considerando as variáveis analisadas em conjunto, percebe-se que o acento tem papel fundamental na ocorrência de processos na fala dos sujeitos dessa amostra. De modo especial, a observância do pé métrico do PB sequência estrutural que é observada para a leitura do acento. Este é um pé binário com "o cabeça" (sílaba forte do pé) à esquerda, conhecido como pé troqueu silábico. Esse tipo de pé métrico é o que fornece a característica do acento-padrão paroxítono (forte-fraco (* .) ou SW) cujo mapeamento se dá na direção da Direita para a Esquerda ${ }^{13}$. Assim, quando se está programando a fala de uma palavra do português, a primeira porção identificada para tal programação são as duas sílabas dentro do pé métrico ou as duas sílabas mais à direita da palavra. Busca-se preservá-lo, pois, possivelmente, este tenha maior peso na identificação da palavra pelo ouvinte. Por exemplo, na palavra 'sapato', as sílabas 'pa' e, 'to' seriam primeiramente identificadas e mais cuidadas na programação motora, já que exercem maior peso na identificação da palavra. Assim, ocorrências como 'papato' (assimilação), ou 'tapato' (substituição) ou mesmo 'pato' (apagamento silábico) seriam formas previsíveis. Do mesmo modo, em casos de dispraxia mais severa 'ao', seria a estrutura preservada no apagamento total de consoantes. Os dados encontrados reforçam as pesquisas internacionais que afirmam que a alteração da estrutura silábica é um aspecto importante da fala de sujeitos com dispraxia verbal $2,4,7,8$.

Assim, os sujeitos evitam apagar sílabas ou segmentos consonantais ou vocálicos que estejam localizados no pé métrico, preferindo substituí-los ou produzi-los corretamente. Ocorrem apagamentos dos segmentos apenas quando esses estão em estruturas silábicas mais complexas como o onset complexo e a coda. Nesse caso, a líquida, segundo elemento do onset complexo (Exemplo: 'pra') e que também aparece na coda (por exemplo 'par'), é apagada.

Já as sílabas que estão fora do pé métrico (póspós-tônica, pré-pré-tônica ou pré-tônica) são aquelas que são alvo maior de processos de apagamento silábico, de apagamentos consonantais e vocálicos.
Portanto, em respeito ao que é canônico para a produção de palavras em PB, as crianças estão mantendo sílabas simples (onset simples) que estejam localizadas dentro do pé métrico (paroxítona).

Em relação às alterações de vogais, este trabaIho só analisou o apagamento da vogal. Observase que, a exemplo das consoantes, o fato de a vogal estar fora do pé métrico da língua, sobretudo na posição pré-pré-tônica e, na posição extramétrica pós-pós-tônica, favorece seu apagamento, enquanto as demais posições (tônica, pré-tônica, pós-tônica) são desfavorecedoras deste. Diante da incapacidade de programar toda a palavra, a criança programa o que se apresenta com maior saliência perceptual, normalmente o conteúdo segmental que está dentro do pé métrico. Esse resultado, comum a crianças em aquisição fonológica típica e atípica, sugere que o pé métrico é fundamental para o reconhecimento da palavra por parte do interlocutor e, por isso, é mantido na produção incompleta da palavra ${ }^{9,12}$.

Talvez a diferença entre as crianças com DV, com aquisição fonológica típica e com desvio fonológico, seja a intensidade com que os apagamentos acontecem. Isso sugere a necessidade de um estudo futuro comparando esses três grupos quanto às variáveis estudadas. $O$ estudo também sugere que palavras dissílabas, com acento paroxítono e estrutura silábica simples (onset simples) são as mais propícias para a inserção de novos fonemas no trabalho de fala com sujeitos com DV, falantes do português brasileiro.

\section{CONCLUSÃO}

Os dados desta pesquisa sugerem que o pé métrico tende a ser mais corretamente produzido, estrutura prosódica na qual ocorre menos apagamentos. Já as sílabas mais afetadas por apagamentos são justamente as que estão fora do pé métrico.

Entre as variáveis selecionadas como relevantes para os apagamentos silábicos, estão a tonicidade, a extensão da palavra e a classe sonora. Além dessas, nos apagamentos consonantais, a estrutura silábica também é relevante. Já no apagamento de vogais, apenas a tonicidade e a estrutura silábica apresentam importância. 


\begin{abstract}
Purpose: to analyze the role of linguistic factors in the process of syllabic, consonantic and vocalic erasing on the speech of subjects with Verbal Dyspraxia. Methods: phonologic analyses of seven subjects (2:6-4:2), with Verbal Dyspraxia diagnostic hypothesis. Results: tonicity, word extension and sound class were the variables selected as relevant for the syllabic erasing. Other than those, on the consonant erasing, the syllabic structure is also relevant. On the vowel erasing only the tonicity and the syllabic structure were statistically significant. Conclusion: data from this research suggest the "metric foot tends to be produced more correctly, a prosodic structure where less erasing take place. The syllables most affected by erasing are those, which are just outside of the "metric foot".
\end{abstract}

KEYWORDS: Apraxias; Speech; Language Development

\section{REFERÊNCIAS}

1. Lewis BA, Freebairn LA, Hansen A, Taylor HG, lyengar S, Shriberg LD. Family pedigrees of children with suspected childhood apraxia of speech. J Commun Dis. 2004; 37(2):157-75.

2. Davis BL, Jacks A, Marquardt TP. Vowel patterns in developmental apraxia of speech: three longitudinal case studies. Clin Linguist Phon. 2005; 19(4):249-74.

3. Shriberg LD, Green JR, Campbell TF, Mcsweeny JL, Scheer AR. A diagnostic marker for childhood apraxia of speech: the coefficient of variation ratio. Clin Linguist Phon. 2003; 17(7):575-95.

4. Betz SK, Stoel-Gammon C. Measuring articulatory error consistency in children with developmental apraxia of speech. Clin Linguist Phon. 2005; 19(1):53-66.

5. Indefrey P, Levelt WJ. The spatial and temporal signatures of word production components. Cognition. 2004; 92(1-2):101-44.

6. Cholin J, Levelt WJM, Schiller NO. Effects of syllable frequency in speech production. Cognition. 2006; 99(2):205-35.
7. Aichert I, Ziegler W. Syllable frequency and syllable structure in apraxia of speech. Brain Lang. 2004; 88(1):148-59.

8. Marquardt TP, Jacks A, Davis BL. Token-to-token variability in developmental apraxia of speech: three longitudinal case studies. Clin Linguist Phon. 2004; 18(2):127-44.

9. Lamprecht RR, Bonilha GGF, Freitas GCM, Mezzomo CL, Oliveira CC, Ribas LP. Aquisição fonológica do portugês. Perfil de desenvolvimento e subsídios para terapia. Porto Alegre: Artmed; 2004. 10. Cedergren HJ, Sankoff D. Variable rules: performance as a statistical reflection of competence. Language. 1974; 50(2):332-55.

11. Scherre M. Introdução ao Pacote VARBRUL para microcomputadores. Rio de Janeiro: Ed. da UFRJ; 1993.

12. Ribas LP. Aquisição das líquidas por crianças com desvio fonológico: aquisição silábica ou segmental?. Rev Letras. 2008; 36:129-149.

13. Massini-Cagliari G. Revisitando o acento do Português Arcaico a partir de uma abordagem otimalista: o padrão dos verbos. Estud Linguist. 2005; 34:1248-53.

RECEBIDO EM: 18/03/2009

ACEITO EM: 01/09/2009

Endereço para correspondência:

Inaê Costa Rechia

Rua Silva Jardim, 1067

Santa Maria - RS

CEP: 97010-491

E-mail: inaerechia@ hotmail.com

Rev. CEFAC, São Paulo 